\title{
Impact of Global Warming on the Vegetation Durable and Distribution Area of Crops in the Humid Subtropical and Mountainous Regions of Georgia
}

\author{
Giorgi Meladze, Maia Meladze \\ Institute of Hydrometeorology at the Georgian Technical University, Tbilisi, Georgia
}

Email address:

meladze.agromet@gmail.com (G. Meladze); meladzem@gmail.com (M. Meladze)

To cite this article:

Giorgi Meladze, Maia Meladze. Impact of Global Warming on the Vegetation Durable and Distribution Area of Crops in the Humid Subtropical and Mountainous Regions of Georgia. American Journal of Environmental Protection. Special Issue: Applied Ecology: Problems, Innovations. Vol. 4, No. 3-1, 2015, pp. 162-167. doi: 10.11648/j.ajep.s.2015040301.35

\begin{abstract}
The surface air temperature in the Eastern and Western parts of Georgia in conditions of global warming, has increased by $0.2-0.5^{\circ} \mathrm{C}$, respectively. By $2030-2050$, the average increase in the annual temperature may reach $1-2^{\circ} \mathrm{C}$. Therefore, the preliminary evaluation of the impact of such an increase on the agrarian sector is important. The increasing and decreasing trends of the duration of the vegetation period and sums of active temperatures and atmospheric precipitations were revealed for the vegetation period in humid subtropical zone of Adjara in West Georgia and mountainous regions of Samtskhe-Javakheti in East Georgia, according to the trend. The increasing trend of the sum of temperatures in the humid subtropical zone of Adjara has reached $52^{\circ} \mathrm{C}$ for half a century (1956-2005). In terms of such a temperature increase, the sum of active temperatures is going to exceed $100^{\circ} \mathrm{C}$ by 2050 what will be beneficial for the ripening of citrus fruits and high productivity of other crops in terms of moderate soil productivity. The increasing trend for the sum of active temperatures in Samtskhe-Javakheti region in the above-said period reached $125^{\circ} \mathrm{C}$ according to the trend, and may double by 2050 reaching $3192^{\circ} \mathrm{C}$. The given sum of active temperatures will improve the productivity of cereals, fruit-trees, vegetables, vine (early, with moderate ripeness) and other crops, in terms of relevant irrigation. According to the current (basic) and future scenario (2020-2050) in Adjara region, by considering $1^{\circ} \mathrm{C}$ increase in air temperature, there are four micro-zones allocated (up to $500 \mathrm{~m}$ a.s.l.) to grow appropriate crops. For Samtskhe-Javakheti region Under the current (basic) and future scenario, the increase in temperature by $2^{\circ} \mathrm{C}$, there are four micro-zones allocated (by $500 \mathrm{~m}$ gradation), to grow appropriate crops.
\end{abstract}

Keywords: Crops, Active Temperature Sum, Scenario

\section{Introduction}

The data analysis of monitoring over the global climate change evidences an increasing trend in surface air temperature. According to the IPCC report, the average annual air temperature has increased by $0.6^{\circ} \mathrm{C}$. The researchers prove that global warming is mainly associated with the anthropogenic impact, and therefore, human activities must be reasonably and purposefully planned. In particular, the concentration of carbon dioxide $\left(\mathrm{CO}_{2}\right)$ in the atmosphere must be reduced, as it has like ,greenhouse effect" resulting in the process of warming in the lower layers of the atmosphere [1].

At the end of the $20^{\text {th }}$ century, the concentration of carbon dioxide increased by $10 \%$ [2], and this trend continues in the $21^{\text {th }}$ century. By 2030, the increase may double what will lead to the temperature increase by $2-3^{\circ} \mathrm{C}[3,4]$. The said problem must be solved by the joint efforts of the world countries. Otherwise, if the climate warming continues for many years, the ecological balance established for many centuries may be negatively influenced. Global climate warming has spread in the Western and Eastern regions of Georgia. The surface air temperature has increased by $0.2-0.5^{\circ} \mathrm{C}$, respectively $[5,6,7]$. The greater temperature increase is observed in east Georgia as compared to west Georgia. Such an increase must be taken into account in the future because the temperature increase may continue and lead to the $1-2^{\circ} \mathrm{C}$ increase in the average multi-year temperature by $2030-2050$. Consequently, we must have some preliminary awareness of the outcomes of such an impact on the economic branches of the country, and agrarian sector in particular, which is a relatively vulnerable branch. 


\section{Study Area \& Methods}

Khelvachauri municipality (humid subtropical region of Adjara) is located $15 \mathrm{~m}$ a.s.l. and Akhaltsikhe municipality (mountainous regions of Samtskhe-Javakheti) - to $1000 \mathrm{~m}$ a.s.l. Sums of active temperatures here is $4400-3000^{\circ} \mathrm{C}$ (respectively) and atmospheric precipitations makes 1360-3080 mm (respectively).

In conditions of global warming, we must identify the sums of active temperatures and atmospheric precipitations, as well as the increasing and decreasing trends of the duration of the vegetation period (in days) in the vegetation period by using the trend method. This allows identifying their changes in time and space. The zones of spreading and normal growing and development of the crops must be identified according to the future scenarios. With this purpose, based on the observation data of Khelvachauri municipality weather station, the subtropical region of Adjara (West Georgia) and according to the mountainous region of Samtskhe-Javakheti of East Georgia (Akhaltsikhe municipality weather station), the materials of current (basic) meteorological observations were developed (1956-2005). The future scenarios (2020-2050) were developed in a similar way calculated with model ECHAM4 and A2 future scenario [6].

\section{Results \& Discussions}

According to the current (basic) and future scenario (at the increase temperature by $1^{\circ} \mathrm{C}$ ) in the humid subtropical region of Adjara, it was established that the transition of average daily air temperature above $10^{\circ} \mathrm{C}$ in spring is observed on 24.III (current) and the transition below $10^{\circ} \mathrm{C}$ in autumn is observed on 3.XII (current). Under the scenario the temperature increase by $1^{\circ} \mathrm{C}$, the transition of average daily air temperature above $10^{\circ} \mathrm{C}$ in spring is observed on 16 .III and the transition below $10^{\circ} \mathrm{C}$ in autumn is observed on 9.XII. So, in case of the increase scenario (at the increase temperature by $1{ }^{\circ} \mathrm{C}$ ), the transition above $10^{\circ} \mathrm{C}$ in spring starts approximately 8 days earlier and ends 6 days later in autumn than in case of the current (basic). Thus, the duration of the vegetation period (in days) increases from 254 days (current) to 268 days (scenario), i.e. by 14 days. Such an expanded period will allow the agricultural workers and farmers to accomplish the soil cultivation works, fertilization, sowing cereals and vegetables, planting seedlings, etc. 8 days earlier in the spring. The duration of vegetation in autumn 6 days longer will promote sowing the autumn crops within the terms envisaged by agricultural methods, gaining lossless harvesting, etc.

In the mountainous region of Samtskhe-Javakheti, the date of the temperature transition above $10^{\circ} \mathrm{C}$ in spring is 22 .IV (current), and the transition below $10^{\circ} \mathrm{C}$ in autumn is $15 . \mathrm{X}$. At the increase temperature by $2^{\circ} \mathrm{C}$ (future scenario), the transition above $10^{\circ} \mathrm{C}$ in spring will occur on 11.IV, and the transition below $10^{\circ} \mathrm{C}$ in autumn will occur on $24 . \mathrm{X}$. The duration of the vegetation period (in days) in Samtskhe-Javakheti region also increases. In particular, in spring, according to the scenario at the increase temperature by $2^{\circ} \mathrm{C}$, the transition of the temperature above $10^{\circ} \mathrm{C}$ starts 11 days earlier and ends 9 days later than with the current (basic). Therefore, the duration of the vegetation period increases from 176 days (current) to 196 days, i.e. by 20 days. The given number of days will allow the agricultural workers and farmers to accomplish spring and autumn works. For the humid subtropical zone of Ajara, the sums of active temperatures above $10^{\circ} \mathrm{C}$ between the above-said dates are calculated, with the sum of the basic temperature of $4400^{\circ} \mathrm{C}$, and it is $4650^{\circ}$ under scenario (at the increase temperature by $1^{\circ} \mathrm{C}$ ). The sum of temperatures under the current (basic) will increase by $250^{\circ} \mathrm{C}$ what will have a favorable impact on the development of citrus cultures, particularly, on full ripening and quality of the fruit at the locations with a less sum of temperatures. Besides, this will allow gaining high-quality harvest of cereals, tea, vine, fruit, technical cultures (tung, laurel, tobacco) and other cultures in terms of proper soil humidity.

The sums of active temperatures are similarly calculated in Samtskhe-Javakheti region between the above-said dates and they make $2880^{\circ} \mathrm{C}$ (current) on average, and $-3510^{\circ} \mathrm{C}$ under the scenario, at the increase temperature by $2^{\circ} \mathrm{C}(2040-2050)$. Such sum of temperatures is beneficial for the areas with crops lacking normal development due to the low sum of temperatures. The impact of global warming on the variation of the sums of active temperatures in Adjara humid subtropical zone is shown as a trend line (Fig. 1).

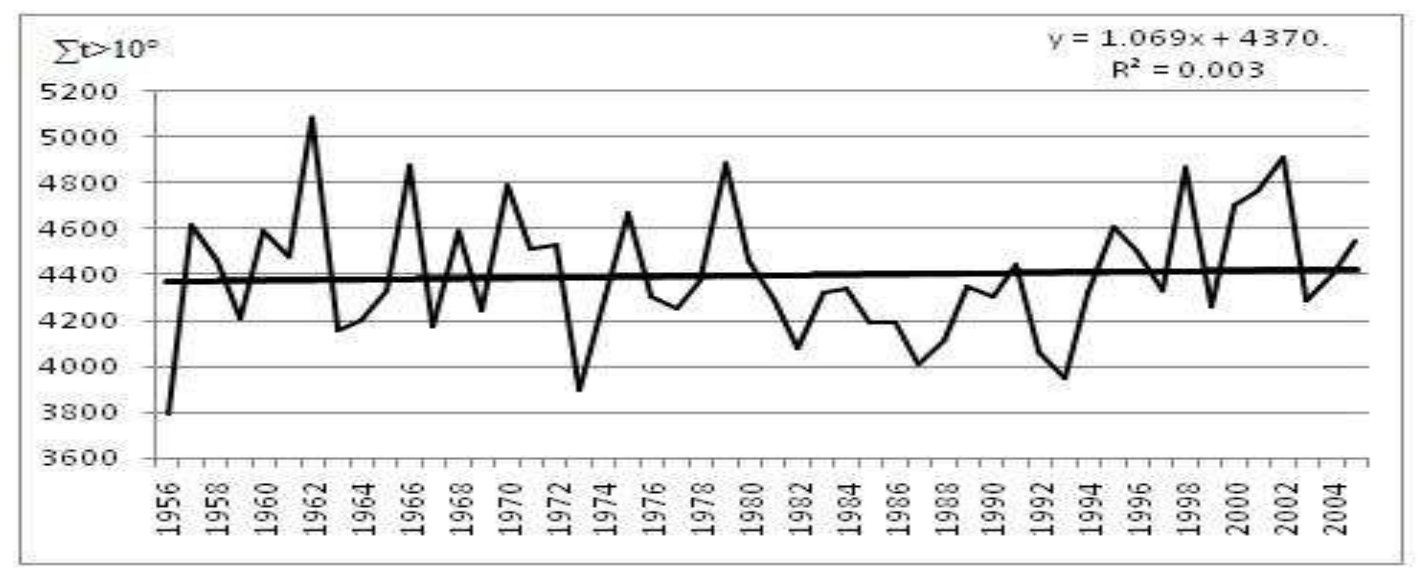

Figure 1. Dynamics of the course and trend line of the sum active temperatures (Khelvachauri) 
The trend line (Fig. 1) clearly shows the increase of the sum of temperatures in the vegetation period. In the initial period (1956), it is $4371^{\circ} \mathrm{C}$ and reaches $4423^{\circ} \mathrm{C}$ at the end of 2005 . In this period ( 50 years) it was revealed that the sum of active temperatures increased by $52^{\circ} \mathrm{C}$. If the temperature increase continues at the same rate, by 2050 , it will be a little more than $100^{\circ} \mathrm{C}$, what will be favorable to gain a high-quality and biologically ripe fruits of citrus cultures. In addition, the productivity of other agricultural crops will improve in terms of optimal soil humidity.

In Samtskhe-Javakheti mountainous region (Fig. 2) the trend line clearly shows the tendency of the increasing sum of active temperatures.

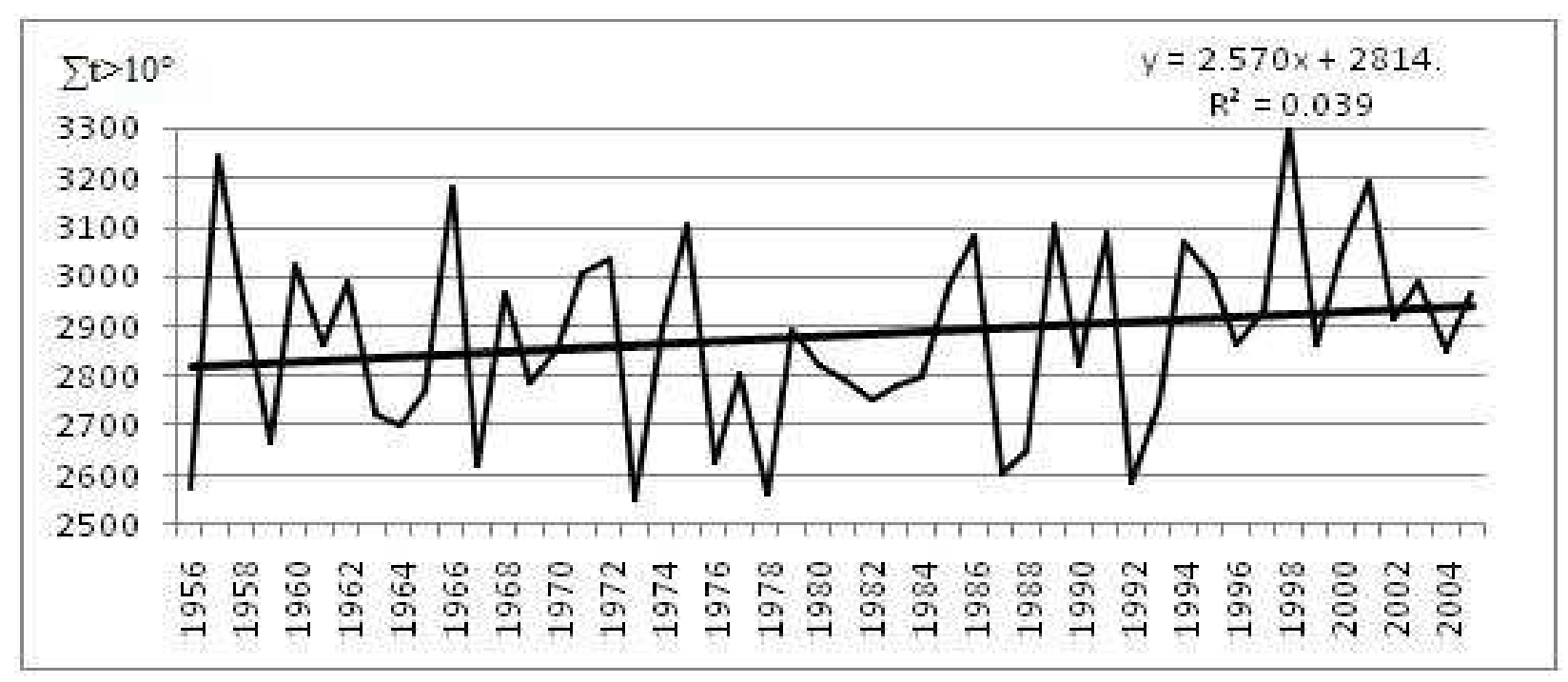

Figure 2. Dynamics of the course and trend line of the sum active temperatures (Akhaltsikhe)

In the initial period $(1956)$, it is $2817^{\circ} \mathrm{C}$ and reaches $2942^{\circ} \mathrm{C}$ by 2005 . The sum of active temperatures in this period increased by $125^{\circ} \mathrm{C}$. If the trend of the temperature increase continues in the vegetation period, it may double by 2050 and reach $3192^{\circ} \mathrm{C}$. Such sum of temperatures will improve the productivity of cereals, fruit, vine (early, of average ripeness), vegetables and other crops in terms of proper irrigation measures.

In conditions of global warming, the areas where the global warming will not have negative outcomes must be selected to grow crops. Consequently, the degree of change of the sums of active temperatures and distribution areas of crops depending on the height from the sea level under current (basic) and future (2020-2050) scenario by 1 and $2^{\circ} \mathrm{C}$ increase in temperature is assessed and taken into account. In this connection, the distribution areas of crops depending on the agro-climatic zones were allocated [8,9]. A zone including the Black Sea coastline and spreading at about $500 \mathrm{~m}$ a.s.l., is identified in the humid subtropical region of Adjara. At every $100 \mathrm{~m}$ height of this zone, there are four micro-zones of distribution of citrus cultures identified and the active temperature sums by $1^{\circ} \mathrm{C}$ temperature increase are fixed [8]. The sum of temperatures in the micro-zone at $100 \mathrm{~m}$ a.s.l. is $4210^{\circ} \mathrm{C}$. The given sum of temperatures ensures full ripening of early and late tangerine every year, and ripening of early orange and grapefruit for 6 or 7 times and late ones for 4 or 5 times in every 10 and more years. The sum of temperatures at $200 \mathrm{~m}$ a.s.l. is $4070^{\circ} \mathrm{C}$, and therefore, full ripening of early tangerine is expected every year and that of late tangerine is expected for 8 or 9 times in every ten or more years. Full ripening of early orange is possible once or twice in every ten years. The sum of temperatures at $300 \mathrm{~m}$ a.s.1. is $3920^{\circ} \mathrm{C}$. In this micro-zone, full ripening of early tangerine is likely for 4 or 5 times and 2 or 3 times in ten or more years for late tangerine varieties. The sum of active temperatures in the micro-zone at $400 \mathrm{~m}$ a.s.l. is $3780^{\circ} \mathrm{C}$. This sum of temperatures does not ensure full ripening of the citrus fruits. As for the lemon, its fruit is desirable to harvest in terms of the sum of temperatures of $3800-4000^{\circ} \mathrm{C}$. In such terms, the lemon fruit is of a light green, partially yellowish color with high content of vitamin „C". Therefore, lemon can be grown in every micro-zone, provided it is protected against the frost in winter [8].

According to the developed future scenario, at the increase in air temperature by $1^{\circ} \mathrm{C}$, the sum of temperatures in the micro-zone at the height of $100 \mathrm{~m}$ is $4340^{\circ} \mathrm{C}$ and it is $4210^{\circ} \mathrm{C}$ at the height of $200 \mathrm{~m}$. In terms of such temperatures, full ripeness of early and late citrus varieties will be possible every year as compared to the above-mentioned (basic) micro-zones (100-200 $\mathrm{m}$ a.s.1.). The sum of temperatures at $300 \mathrm{~m}$ a.s.l. is $4080^{\circ} \mathrm{C}$. In this micro-zone, full ripening of tangerine is possible every year, while full ripening of early orange is possible for 4 or 5 times and that of late orange and grapefruit is possible for 3 or 4 times in every ten years. The sum of active temperatures at $400 \mathrm{~m}$ a.s.l. decreases and makes $3920^{\circ} \mathrm{C}$. In terms of such a sum of temperatures, full ripening of early tangerine is possible for 7 or 8 times, that of late tangerine is possible for 5 or 6 times in ten years, while full ripening of early orange is possible once or twice in every ten years. In conditions of global warming under the future 
scenario in temperature increase by $1^{\circ} \mathrm{C}$, the sum of active temperatures is increased, as mentioned already. Therefore, full ripeness of tangerine fruit in the humid subtropical zone of Ajara region is possible at the height of 300 to $400 \mathrm{~m}$. Orange and grapefruit are an exception (with full ripeness once or twice in every ten years). According to the future scenario, as a result of the increased sum of temperatures $\left(150-200^{\circ} \mathrm{C}\right)$, the productivity and quality of other agricultural crops (cereals, tea, vine, vegetables, nut, kiwi (actinidia), technical and essence varieties) will improve in terms of optimal soil humidity.

In the vegetation period, the atmospheric precipitations, along with the sums of active temperatures, play an important role in the growth and development of crops and gaining the harvest. In this connection, the sums of atmospheric precipitations in the given period (1956-2005) was determined in Adjara region and the relevant dynamics were drafted according to the trend (Fig. 3).

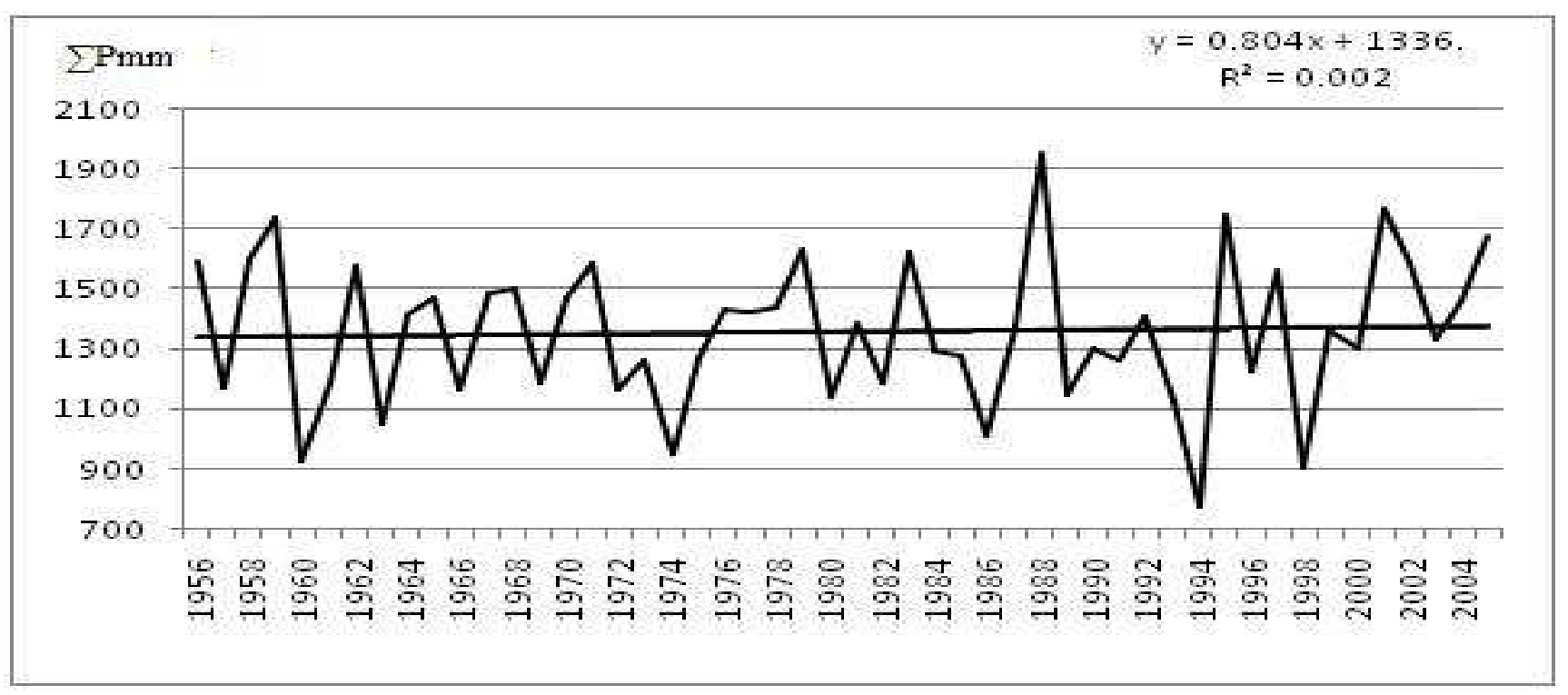

Figure 3. Dynamics of the course and trend line of the atmospheric precipitations (Khelvachauri)

In the initial period (1956), the sum of atmospheric precipitations was $1337 \mathrm{~mm}$ and reached $1377 \mathrm{~mm}$ after 50 years (in 2005). The tendency of increase of the atmospheric precipitations is $40 \mathrm{~mm}$, showing an increase of $8 \mathrm{~mm}$ in every ten years. If this increasing tendency continues, by 2050, the amount of precipitations may double in the above-said zone what will slightly improve the soil humidity.

In Samtskhe-Javakheti mountainous region of East Georgia, there were 4 agro-climatic zones allocated in connection to global warming. The first zone spreads to $1000 \mathrm{~m}$ a.s.l., and the sum of active temperatures here is $2800^{\circ} \mathrm{C}$ (current). According to the scenario, in temperature increase by $2^{\circ} \mathrm{C}$, it is $-3320^{\circ} \mathrm{C}$. The sum of temperatures is surely increased what will improve the productivity and quality of the cereals (spring wheat, maize, etc.), vine (early varieties) and fruit. This will also boost the harvest of vegetables and potato, with the second harvest possible to gain and the vine (late varieties) will be possible to distribute, but with high-quality full quality ripeness only for 7 or 8 times in every ten years. The second zone spreads at about $1500 \mathrm{~m}$ with the sum of active temperatures of $2000^{\circ} \mathrm{C}$ (current). Under future scenario (at the increase temperature by $2^{\circ} \mathrm{C}$ ), the sum of active temperatures is $2450^{\circ} \mathrm{C}$ (showing an increase of $450^{\circ} \mathrm{C}$ ). Surely, in such terms, it will be possible to expand the distribution area of fruit trees, berries, cereals, vegetables, potato and other cultures, and production area of cattle succulent root crops. The third zone spreads at about $2000 \mathrm{~m}$ with the current (basic) sum of active temperatures not exceeding $1200^{\circ} \mathrm{C}$, and is $1580^{\circ} \mathrm{C}$ under scenario (at the increase temperature by $2^{\circ} \mathrm{C}$ ). The increased sum of temperatures will promote the growth and development and high productivity of autumn and spring crops, early pomaceous fruit: apple, pear, berries: black and red currants, willow-leaved sea-buckthorn, raspberries, vegetables, potato, as well as cattle succulent root crops and pastures and hay-making meadows. The fourth zone spreads at about 2500 $\mathrm{m}$ with quite decreased sum of active temperatures, with the current (basic) it is $1030^{\circ} \mathrm{C}$ at the height of $2100 \mathrm{~m}$ and it is $390^{\circ} \mathrm{C}$ at the height of $2500 \mathrm{~m}$. The latter sum of temperatures is not suitable even for growing grass as a pasture. Under the future scenario (at the increase temperature by $2^{\circ} \mathrm{C}$ ), the sum of active temperatures will increase to $1400^{\circ} \mathrm{C}$ at the height of $2100 \mathrm{~m}$ and it will be $700^{\circ} \mathrm{C}$ at the height of $2500 \mathrm{~m}$. Such sum of temperatures as compared to the current, creates better conditions for such cultures to spread as early wheat (autumn and spring), barley, vegetables, potato, berries (black and red currants), willow-leaved sea-buckthorn, chokeberry and above-mentioned cattle succulent root crops at the height of 2200-2300 m, and pastures and hay-making meadows at the height of 2300-2500 m.

Normal growth and development of these cultures in the vegetation period besides the warmth, depends on the atmospheric precipitations, while Samtskhe-Javakheti mountainous region is less provided with the latter. Therefore, the precipitations in the vegetation period in different years (1956-2005) were assessed by identifying and drafting the 
dynamics of the course of atmoshperic precipitations on the background of global warming (Fig. 4).

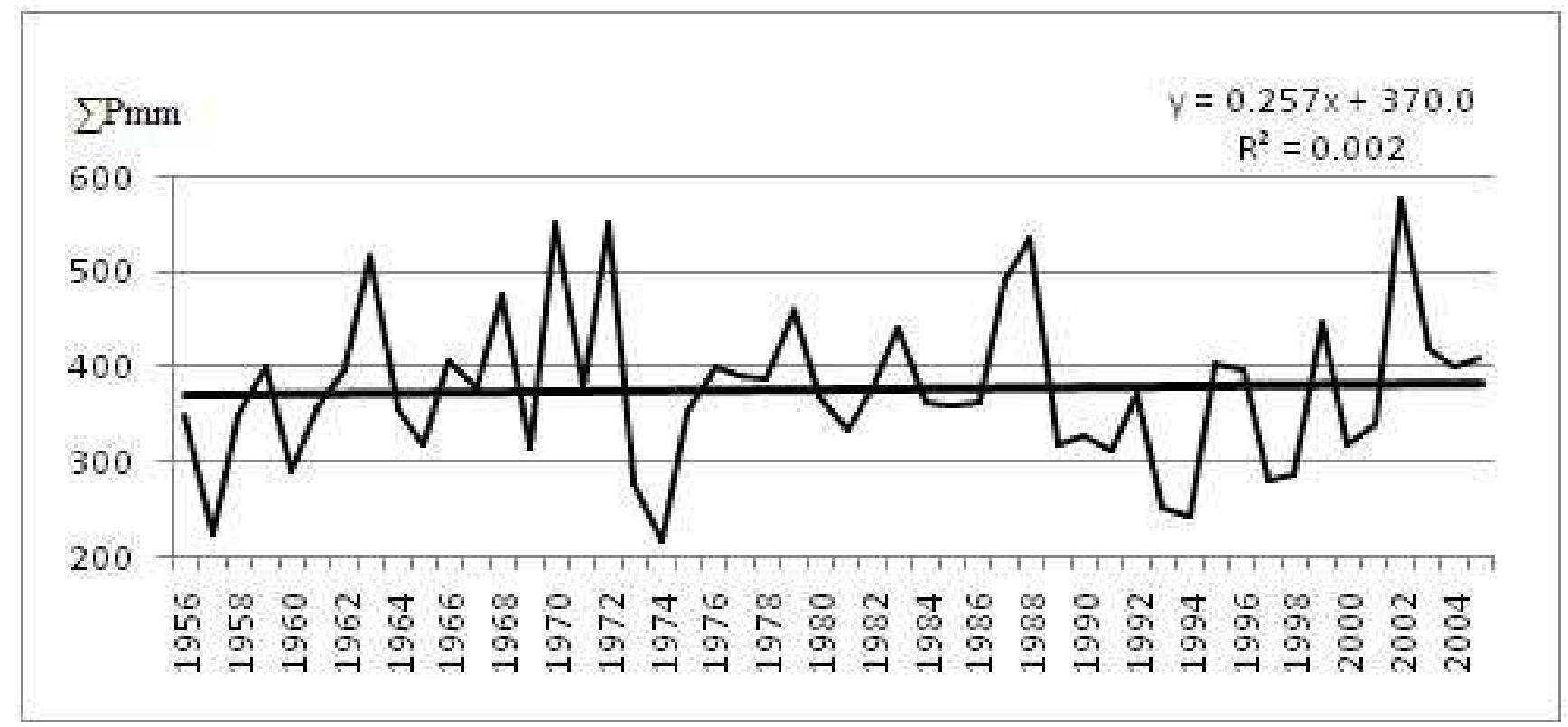

Figure 4. Dynamics of the course and trend line of the atmospheric precipitations (Akhaltsikhe)

In this period (in 1956), the sum of atmospheric precipitations was $370 \mathrm{~mm}$ according to the trend, and it is 383 $\mathrm{mm}$ after 50 years (in 2005). As one can see, an increasing trend of the precipitations was fixed (by $13 \mathrm{~mm}$ ). By 2040-2050, this figure may double (making $26 \mathrm{~mm}$ ), but cannot create optimal conditions for the growth and development of crops. Therefore, a stable productivity can be achieved by providing the proper soil humidity where this is possible.

The nomogram of heat provision in the vegetation period in case of the current (1956-2005) and future scenarios
(2020-2050) by $1^{\circ} \mathrm{C}$ temperature increase was designed for Adjara humid subtropical zone [10] by using the sum of the above-given temperature data and relevant agro-meteorological method. The similar nomogram of heat provision following the current (1956-2005) and future scenario (2020-2050) by $2^{\circ} \mathrm{C}$ temperature increase was designed for Samtskhe-Javakheti mountainous region [11]. By using the nomograms, the provision (\%) of active temperature sums with the current and future scenario by $1^{\circ} \mathrm{C}$ and $2^{\circ} \mathrm{C}$ increases in every ten years and more was calculated (Table 1).

Table 1. Provision by active temperature sums (above $10^{\circ} \mathrm{C}$ )

\begin{tabular}{|c|c|c|c|c|c|c|c|c|}
\hline \multirow{2}{*}{ Regions } & \multirow{2}{*}{ Year } & \multicolumn{7}{|c|}{ Provision by active temperature sums, $\%$} \\
\hline & & 95 & 90 & 70 & 50 & 30 & 10 & 5 \\
\hline \multirow{2}{*}{ Adjara } & 1956-2005 Current (basic) & 4080 & 4150 & 4290 & 4400 & 4550 & 4880 & 4920 \\
\hline & 2020-2050 Scenario, $1^{\circ} \mathrm{C}$ - increase & 4370 & 4430 & 4540 & 4650 & 4810 & 5020 & 5070 \\
\hline \multirow{2}{*}{$\begin{array}{l}\text { Samtckhe- } \\
\text { Javakheti }\end{array}$} & 1956-2005 Current (basic) & 2470 & 2540 & 2720 & 2880 & 2980 & 3170 & 3240 \\
\hline & 2020-2050 Scenario, $2^{\circ} \mathrm{C}$ - increase & 2960 & 3090 & 3350 & 3510 & 3650 & 3900 & 4010 \\
\hline
\end{tabular}

\section{Conclusion}

The results of the study evidence that the global warming has a clear impact on the increase of active temperatures sums. In particular, in case of temperature increase by $1^{\circ} \mathrm{C}$ under the scenario, it increases by $250^{\circ} \mathrm{C}$ on average, and in case of temperature increase by $2^{\circ} \mathrm{C}$, it increases by $500^{\circ} \mathrm{C}$ or more. Consequently, the distribution area of the plants will expand and the zones will spread higher: the humid subtropical zone of Adjara will rise by $100-150 \mathrm{~m}$ and Samtskhe-Javakheti mountainous zone will rise up to $200-300 \mathrm{~m}$ as compared to the present areas of distribution. This suggests that the agricultural workers and farmers will be able to rationally spread the profitable crops. The vegetation period in the humid subtropical zone of Adjara under scenario by the $1^{\circ} \mathrm{C}$ temperature increase, will be prolonged by 14 days, and it will be prolonged by 20 days in Samtskhe-Javakheti mountainous zone according to the scenario by $2^{\circ} \mathrm{C}$ temperature increase. These indicators will help realize the agro-technical measures under optimal conditions.

\section{References}

[1] H.S. Mavi, G.I. Tupper. Agrometeorology: Principles and Applications of Climate Staties in Agriculture. Binghamton, HY USA. The Haworth Press Ins., Food Products Press ${ }^{\circledR}, 2004$, p. 364.

[2] Human Development Report. Fighting Climate Change: Human Solidarity Divided Word. Published for the United Nations Development Programme (UNDP), 2007-2008, p. 31. 
[3] Impacts of Desertification and Drought and other Extreme Meteorological Events. Prepared by Gathara S.T. Geneva, Switzerland, 2006, p. 88.

[4] H.P. Das, T.I. Adamenko, K.A. Anaman, R.G. Gommes and G. Johnson. Agro-meteorology Related to Extreme Events. World Meteorological Organization - Geneva - Switzerland, 2003, p. 152.

[5] K.Tavartkiladze, E.Elizbarashvili, D.Mumladze, J.Vachnadze. Empirical Model of the Change of Overground Air Temperature Field. Tbilisi, 1999, p. 106

[6] Georgia's Second National Communication to the UNFCCC. Ministry of Environmental Protection and Natural Researches - UNPP, Tbilisi, 2009, p. 237.

[7] K.Tavartkiladze, N.Begalishvili, T.Tsintsadze, A.Kikava. Influence of Global Warming on the Near-Surface Air Temperature Field in Georgia. Bulletin of The Georgian National Academy of Sciences, vol.6, № 3, 2012, pp. 55-60.
[8] G.Meladze, M.Meladze. Influence of the Climatic Global Warming on Agrometeorological Zone of Humid Subtropics of Georgia. Geography of Georgia, TSU, №6-7, 2008, pp. 95-101.

[9] G.Meladze, M.Tutarashvili, M.Meladze. Influence of Global Warming on Changes of Agroclimatic Zones. Proceedings of Hydrometeorology Institute, vol.115, 2008, pp. 97-104.

[10] G.Meladze, M.Meladze. Change of Agroecological Zones under the Future Scenario (2020-2050 year) in the Conditions of Global Warming. Collection of Papers of International Conference. Geographical Society of Georgia, I.Javakhishvili Tbilisi State University, 2011, pp. 28-32.

[11] G.Meladze, M.Meladze. Scenarios of Distribution of Zones Agricultural Crops and Reception of Two Yields in the Conditions of Global Warming (2020-2050, on an example of Dedoplistskaro). International Scientific Conference - Pressing Problems in Hydrometeorology and Ecology. Proceedings of Hydrometeorology Institute, vol.117, 2011, pp. 70-81. 